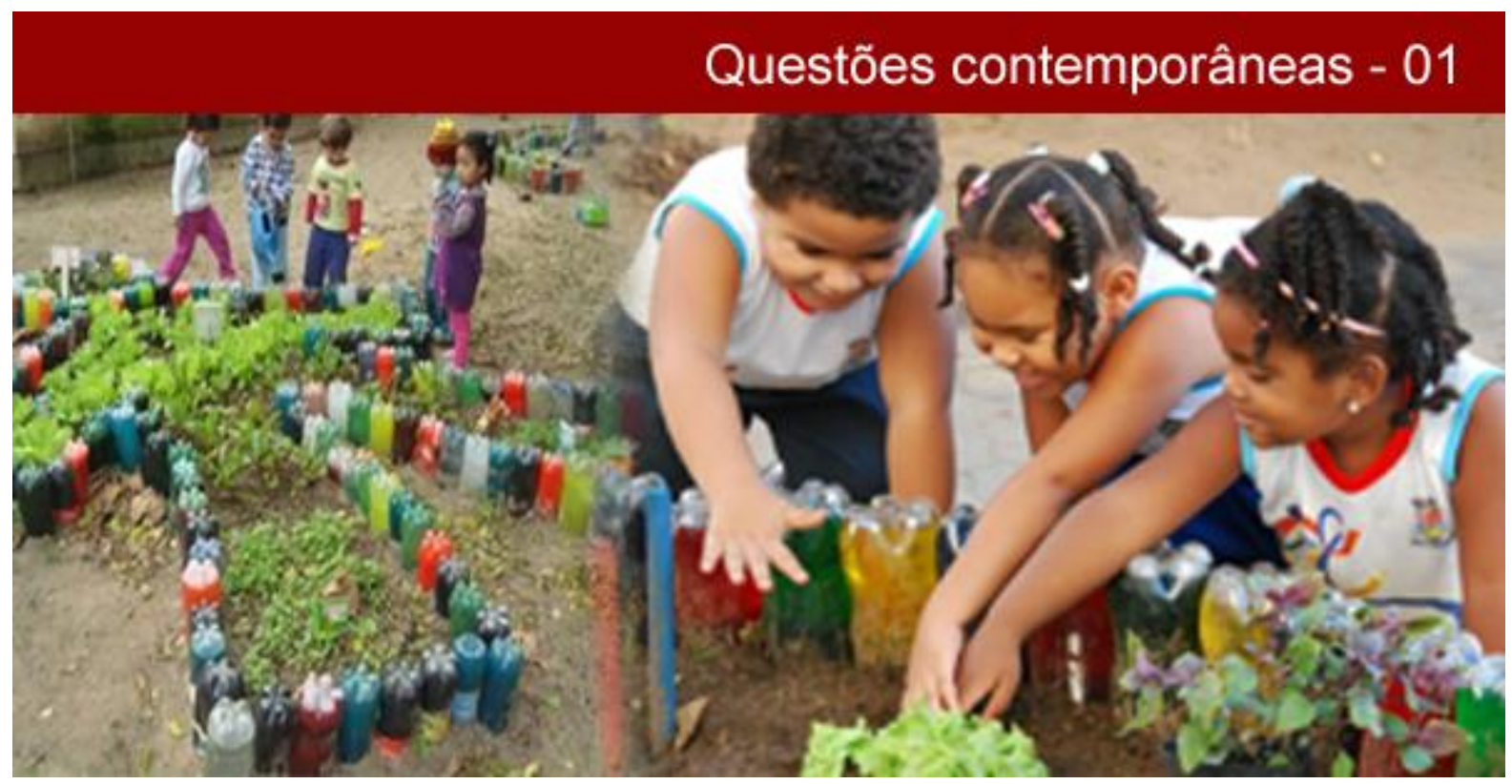

\title{
HORTA ESCOLAR: ALTERNATIVA PARA PROMOVER EDUCAÇÃO AMBIENTAL E DESENVOLVIMENTO SUSTENTÁVEL NO CARIRI PARAIBANO
}

Carlos Antônio Gonçalves da Costa

Engenheiro Agrônomo - CCA/UFPB.

José Thyago Aires Souza

Mestrando em Agronomia PPGA/UFPB, Areia-PB.

\section{Daniel Duarte Pereira}

Professor Doutor CCA/UFPB.

Resumo: A educação ambiental deve ser inserida no currículo do ensino médio bem como deve ser trabalhada de forma interdisciplinar buscando contextualizar com a realidade local. Portanto, este trabalho objetivou retratar e analisar a inserção de um projeto de educação ambiental utilizando a horta como instrumento para proporcionar um estudo baseado em várias áreas do conhecimento oportunizando um aprendizado contextualizado e a formação de cidadãos conscientes e críticos com as questões ambientais. A pesquisa foi realizada no município de Gurjão - PB. Ressalta-se que a horta escolar pode ser considerada um laboratório a céu aberto e que deve ser aproveitado por todas as disciplinas. Tendo em vista o atual modelo de desenvolvimento que vem esgotando os recursos naturais tornando-os cada vez mais escassos - ainda mais no Nordeste brasileiro - torna-se necessária uma interferência no sentido de minimizar estes impactos e, como visto neste trabalho, a escola se apresenta como ambiente particularmente propício a este debate.

Palavras-chave: Meio ambiente. Escola. Ensino. Agricultura. Sustentabilidade.

\section{SCHOOLGARDEN: ALTERNATIVE FOR PROMOTING ENVIRONMENTAL EDUCATION AND SUSTAINABLE DEVELOPMENT IN CARIRI PARAIBANO}

Abstract: Environmental education must be inserted into the high school curriculum and should be worked in an interdisciplinary way seeking to contextualize with local realities. Therefore, this study aimed to portray and analyze the inclusion of an environmental education project using the garden as a tool to provide a study based on several areas of knowledge providing opportunities a contextual learning and the formation of conscious citizens and critical environmental issues. The survey was conducted in the municipality of Gurjão - PB. It is noteworthy that the school garden can be considered an open-air laboratory and should be used by all disciplines.

\section{POLÊM!CA | Revista Eletrônica da Uerj}

Rua São Francisco Xavier, 524, $2^{\circ}$ andar - BL D, sl 2025 - Maracanã

Tels.: +55 $212334-0888$ / 0887

http://www.labore.uerj.br/ - laboreuerj@yahoo.com.br 
Given the current development model that is depleting natural resources making them increasingly scarce - even more in the Brazilian Northeast - interference becomes necessary to minimize these impacts and, as seen in this work, the school it presents as particularly appropriate framework for this debate

Keywords: Environment. School. Education. Agriculture. Sustainability.

\section{Introdução}

O modelo de desenvolvimento consumista atual promove crescente degradação dos recursos naturais com consequências na qualidade de vida, modificando assim hábitos sociais. Tais consequências têm apresentado reflexos negativos nas características do planeta e, assim, no cotidiano das pessoas.

Nesta perspectiva, vários setores da sociedade vêm desencadeando discussões sobre a necessidade de desenvolver ações, programas de sensibilização-conscientização que visem a construção de novos valores e atitudes, ou seja, promover urgentemente a disseminação de um processo educacional, com ações didáticas e pedagógicas voltadas para a sustentabilidade dos recursos naturais (LOZANO \& MUCCI, 2005; ABILIO \& FLORENTINO, 2008). Neste contexto, a escola torna-se o ponto de partida para o início das discussões sobre as questões relacionadas ao meio ambiente, sendo estas trabalhadas de forma interdisciplinar para a formação de cidadãos críticos e sensibilizados para com os problemas ambientais.

Segundo Abílio e Guerra (2005), a escola, tendo em vista a importância que exerce no processo de formação social, cultural, humana e ética da sociedade, se apresenta como um dos locais mais propícios para o desenvolvimento de atividades com enfoque educativo relacionado ao ambiente em que vivemos.

A educação ambiental figura como instrumento na promoção do desenvolvimento sustentável, vez que, amparada na ética ecológica, gera uma conscientização acerca da preservação do planeta. Ou seja, devido ao seu compromisso com o desenvolvimento humano e ambiental, auxilia para o despertar da percepção sustentável por meio de mudanças nos valores, nas ações, nos pensamentos, nas metodologias, entre outros hábitos humanos, sob o fundamento de uma ética ambientalista, assim entendida como a exteriorização dessa consciência (MASSINE, 2010).

De acordo com Milaré (2009) a educação ambiental tem um papel integrador: combina disciplinas, saberes, ensinamentos, aprendizados, práticas. Sob o ponto de vista pedagógico e educacional, ela contribui para dar unidade e convergência aos diferentes tratamentos que se encontram nos sistemas educacionais. Portanto, a educação ambiental figura como ferramenta para conservar a natureza, auxiliando no desenvolvimento sustentável de uma sociedade ciente de seu papel ambiental, se mostrando para tanto capaz de renovar valores e alterar dogmas presentes na relação entre o homem e o meio ambiente, considerando uma nova dimensão que se incorpora no processo de ensino (SANTOS, 1997).

Inserir no currículo escolar a educação ambiental, portanto, torna-se fundamental para o desenvolvimento dos educandos, tornando-os cidadãos conscientes e críticos com as questões relacionadas ao meio ambiente. Definir educação ambiental é falar sobre educação dando-lhe uma nova dimensão, contextualizada e adaptada à realidade interdisciplinar e vinculada aos temas ambientais locais e globais (GUERRA \& ABILIO, 2005).

No ano de 2009, com a implantação pelo Governo Federal do Programa Ensino Médio Inovador (ProEMI), os educandos tiveram a oportunidade de passar mais tempo na escola e consequentemente ampliar

\section{POLÊM!CA | Revista Eletronica da Uej}


seus conhecimentos, pois o objetivo deste projeto é: apoiar e fortalecer o desenvolvimento de propostas curriculares inovadoras nas escolas de ensino médio, ampliando o tempo dos estudantes na escola e buscando garantir a formação integral com a inserção de atividades que tornem o currículo mais dinâmico, atendendo também as expectativas dos estudantes do Ensino Médio e às demandas da sociedade contemporânea (MEC, 2015).

O programa propõe a introdução no currículo dos alunos de oito macrocampos, sendo eles: Acompanhamento Pedagógico, Iniciação Científica e Pesquisa, Cultura Corporal, Cultura e Artes, Comunicação e uso de Mídias, Cultura Digital, Participação Estudantil e Leitura e Letramento, para dar início a maiores possibilidades para a melhoria do processo ensino-aprendizagem com o desenvolvimento de projetos nas mais diversas áreas do conhecimento, promovendo um avanço nas práticas pedagógicas.

Dentre os macrocampos, destaca-se, neste trabalho, o de Participação estudantil, visto que possibilita o desenvolvimento de metodologias e oportunidades que ampliem as condições de participação e assegurem a pluralidade de manifestação da juventude, estabelecendo formas de apoio para o desenvolvimento de alternativas estruturadas de organização (como construir e/ou fortalecer a Com-Vida - Comissão de Meio Ambiente e Qualidade de Vida na Escola, Grêmio, dentre outros), representação e participação estudantil no contexto escolar e social (SILVA et al. 2013).

A partir da implantação do ProEMI - considerando em especial o que sugere este macrocampo supracitado - e de várias discussões sobre os problemas ambientais, alimentação saudável, sustentabilidade e qualidade de vida, percebe-se a necessidade da implantação de atividades curriculares voltadas à temática de desenvolvimento sustentável, como uma horta escolar, por exemplo, cuja apropriação e realização em caso específico é o objeto deste artigo

Como afirma Cribb (2010), as atividades realizadas em ambientes abertos, como na horta escolar, contribuem, dentre outros fatores, para os alunos compreenderem o perigo na utilização de agrotóxicos para a saúde humana e para o meio ambiente; proporciona uma compreensão da necessidade da preservação do meio ambiente escolar; desenvolve a capacidade do trabalho em equipe e da cooperação; e proporciona um maior contato com a natureza, já que crianças dos centros urbanos estão cada vez mais afastadas dela. Proporciona também a modificação dos hábitos alimentares dos alunos, além da percepção da necessidade de reaproveitamento de materiais tais como: garrafas pet, embalagens tetra pak, copos descartáveis, entre outros. Tais atividades auxiliam no desenvolvimento da consciência de que é necessário adotarmos um estilo de vida menos impactante sobre o meio ambiente bem como a integração dos alunos com a problemática ambiental vivenciada.

Numa horta escolar há, ainda, a possibilidade de se trabalhar diversos temas, dentre os quais, os conceitos, princípios e o histórico da agricultura, a importância da educação ambiental e das hortaliças para a saúde, além das aulas práticas onde se trabalham as formas de plantio, o cultivo e o cuidado com as hortaliças (CRIBB, 2010).

Neste contexto, o presente trabalho objetiva retratar e analisar a inserção de um projeto de educação ambiental na escola e sua importância, utilizando a horta como instrumento para proporcionar um estudo

\section{POLÊM!CA | Revista Eletronica da aej}


baseado em várias áreas do conhecimento oportunizando um aprendizado contextualizado às demandas sociais atuais.

\section{Material e Métodos}

Esta pesquisa foi realizada no município paraibano de Gurjão, localizado na microrregião do Cariri Ocidental Paraibano (Figura 1), entre os meses de maio e dezembro de 2013. Esta localidade do estado apresenta, segundo Nascimento e Alves (2008), diferentes formações de vegetação reunidas pelas mais variadas transições edafoclimatológicas, distante a pouco mais de $300 \mathrm{~km}$ de João Pessoa (capital), com área total de $11.689 \mathrm{~km}^{2}$, sendo esta representante de pouco mais de $20 \%$ do Estado.

O clima do município, segundo a classificação de Köeppen, é do tipo BSwh', isto é, semiárido quente. Os dados pluviométricos indicam que a região apresenta precipitação média anual variando entre 350 e 600 mm, mas observa-se que a maior concentração deste total ocorre em período aproximado de dois a quatro meses. As temperaturas mínimas variam de 18 a $22^{\circ} \mathrm{C}$ (meses de julho e agosto) e as máximas situam-se entre 28 e $31^{\circ} \mathrm{C}$ (meses de novembro e dezembro). Quanto à evaporação, os dados obtidos a partir de tanque classe A, variam entre 2.500 a $3.000 \mathrm{~mm}$ (NASCIMENTO \& ALVES, 2008). Estas condições climáticas intensificam a necessidade de se estabelecer atividades sustentáveis, como as hortas, para que seja proporcionada à população a possibilidade de produzir seus próprios alimentos e também gerar renda a partir da produção hortícola.

A cobertura vegetal presente é do tipo Caatinga, com características típicas das regiões nordestinas mais áridas, esta vegetação é praticamente composta por cactos e arbustos com plantas caducifólias e subcaducifólias. Apresentando uma desuniformidade marcante, tendo, pelo menos, três níveis: o primeiro, chamado de arbóreo, com uma altura variada de oito a doze metros, árvores de ótimo porte; o segundo, o arbustivo, com uma altura de dois a cinco metros; o terceiro, herbáceo, com menos de dois metros (MALVEZI, 2007).

Figura - 1: Localização Geográfica do Município de Gurjão-PB

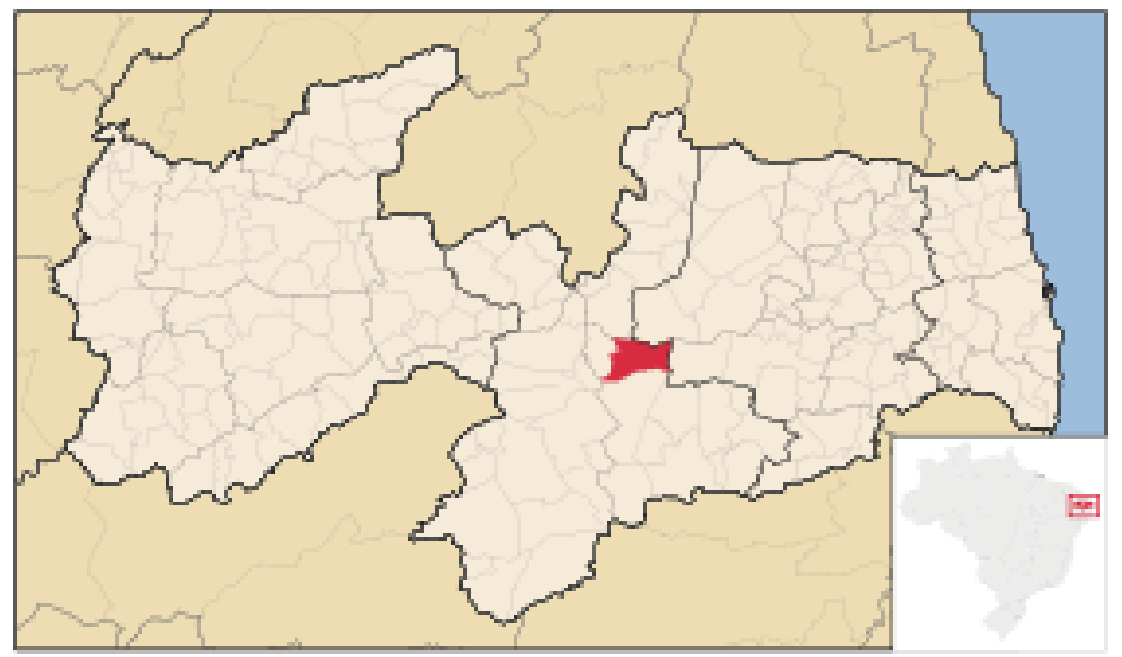

Fonte: CPRM, 2005.

\section{POLÊM!CA | Revista Elêrónica da Uej}


A horta foi escolhida como instrumento pedagógico devido ao ambiente em torno do dia-a-dia dos alunos da região, pois este município é constituído na sua maioria por população rural, o que torna propício o uso desta ferramenta. Através da implantação de uma horta na escola, pode-se proporcionar aos alunos um ambiente de aprendizado sobre diversos assuntos, como o conhecimento sobre agricultura e a importância de uma alimentação saudável com o consumo de hortaliças.

Participam do projeto alunos das turmas $1^{\circ}$ Ano A e B, e $3^{\circ}$ ano A, representando o universo de 56 alunos da Escola Estadual de Ensino Médio Juarez Maracajá, localizada no município de Gurjão - Paraíba (Figura 2). Esta escola foi escolhida por ser a maior escola presente no município, já o que levou a seleção destas turmas foi a faixa etária dos alunos, entre 13 e 15 anos de idade.

A introdução desta atividade foi proposta durante a aula de Geografia a partir da possibilidade de disposição de recursos por parte do governo e da discussão entre professor e alunos sobre a inserção do macrocampo na escola. Foi firmado um contrato didático entre ambos com o intuito de flexibilizar o currículo e dinamizar o macrocampo de Participação Estudantil. A proposta destaca a inserção da educação ambiental por meio da implantação da horta, pela qual pode-se trabalhar alternativas de manejo de solo-água, a importância das hortaliças na alimentação, técnicas de produção, o trabalho cooperado e participativo, e a reciclagem - pois os canteiros foram confeccionados com garrafas Pet.

Cabe ressaltar que antes da implantação da horta os alunos tiveram a oportunidade de discutir a educação ambiental e como esta poderia contribuir para o desenvolvimento de uma sociedade; realizaram pesquisas sobre as hortaliças, recursos hídricos, solo e técnicas de manejo.

Finalizada as pesquisas e discussões que antecedem a implantação da horta os educandos partiram para a intervenção e confecção dos canteiros iniciando com a escolha da área para introdução do projeto; em seguida realizaram a limpeza da área e marcação dos canteiros e, posteriormente, realizaram em grupo uma catação de garrafas pets para confeccioná-los. O projeto foi implantado em maio de 2013, como citado anteriormente, e será desenvolvido por tempo indeterminado.

Figura - 2: Fachada da Escola Juarez Maracajá Gurjão-PB

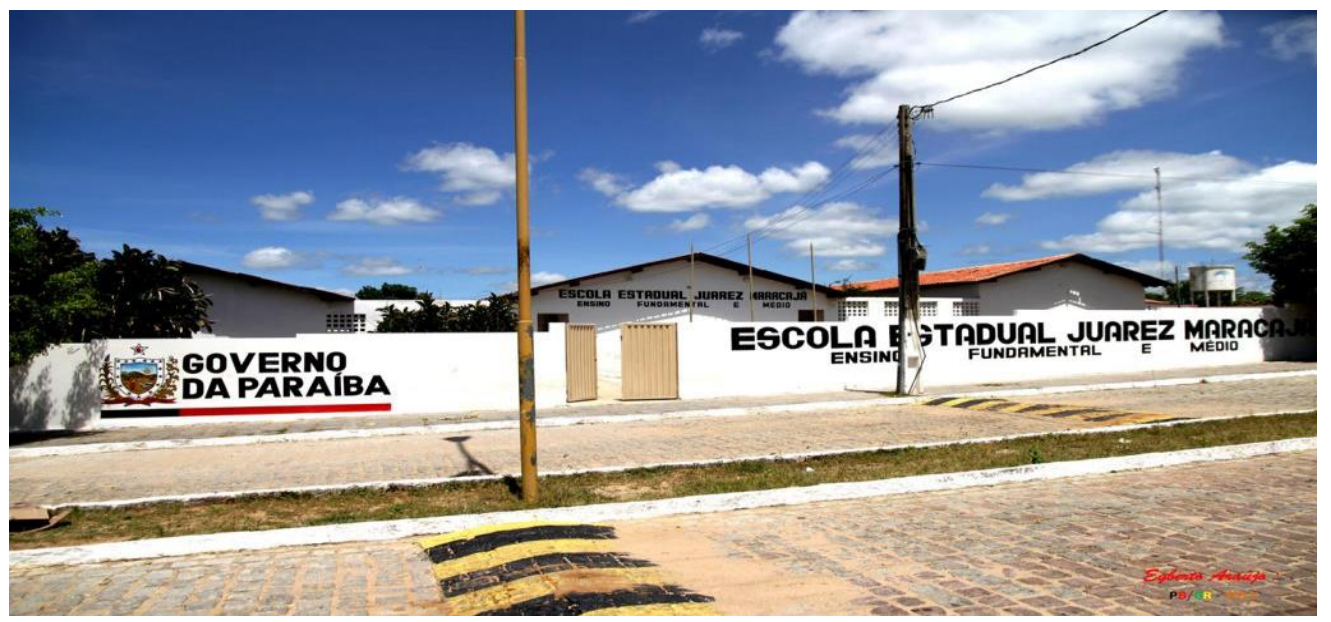

Fonte: Acervo Carlos Antônio Gonçalves da Costa (2013).

\section{POLÊM!CA | Revista Eletrônica da Uerj}

Rua São Francisco Xavier, 524, $2^{\circ}$ andar - BL D, sl 2025 - Maracanã

Tels.: +55 $212334-0888$ / 0887

http://www.labore.uerj.br/ - laboreuerj@yahoo.com.br 
Para confecção dos canteiros foram utilizados vários formatos e dimensões que variam de 2,0 a 5,0m de comprimento, $1,0 \mathrm{~m}$ de largura e $0,30 \mathrm{~cm}$ de profundidade, espaçamento entre as chamadas "ruas" de $0,5 \mathrm{~cm}$ para facilitar o manejo dos canteiros. Em uma pequena vala de $0,20 \mathrm{~cm}$ de profundidade colocam-se as garrafas pet com o gargalo para baixo, em seguida coloca-se areia para dar apoio às garrafas, colocando uma lona/saco plástico no interior dos canteiros com a finalidade de evitar a infiltração da água no solo, evitando o desperdício deste recurso tão escasso na região.

No primeiro ciclo de produção foram plantados coentro, cebolinha, pimentão, tomate e alface; culturas escolhidas de acordo com o hábito alimentar dos alunos e de toda equipe da escola. No sentido de demonstrar alternativas de controle de eventuais pragas que venham a prejudicar o desenvolvimento das culturas, fez-se uso de algumas técnicas de manejo como, por exemplo, o consórcio de plantas utilizando ervas medicinais, introdução de estercos bovinos, catação de insetos. Os insumos necessários para a implantação da horta foram comprados com recursos próprios da escola.

Destaca-se que na delimitação dos canteiros utilizou-se do cultivo da palma forrageira consorciada com milho, demonstrando a técnica da intercalação com as culturas como forma de manejo do solo. Para que a estrutura da horta estivesse concluída foram necessários 2 horários de 45 minutos cada de cada turma por uma semana.

\section{Resultados e Discussão}

Com a implantação da horta na escola os educandos tiveram a possibilidade de realizar pesquisas em diversas áreas do conhecimento, pois este espaço pode ser considerado um laboratório a céu aberto, contribuindo para estimular os alunos a realizar pesquisas científicas e para a promoção de um ensino de qualidade dentro do ambiente escolar.

Neste projeto, os alunos, além do cultivo de hortaliças como cenoura, alface, coentro, pimentão, tomate, realizaram o consorciamento com outras culturas comestíveis, como batata doce, jerimum, feijão, milho e fava, além da palma forrageira, que serve como alimentação para os animais da região e é utilizada para delimitar os canteiros, e ervas medicinais para servir de repelentes aos insetos, bem como espécies frutíferas (Tabela 1).

Tabela - 1: Culturas plantadas no Projeto Horta na Escola Gurjão - Paraíba

\begin{tabular}{c|c|c|c}
\hline HORTALIÇAS & ERVA MEDICINAL & FRUTAS & OUTRAS \\
\hline Alface & Hortelã miúdo & Acerola & Feijão \\
Cenoura & Hortelã graúdo & Mamão & Milho \\
Beterraba & Cidreira & Melão & Batata Doce \\
Coentro & Capim Santo & Melancia & Jerimum \\
Cebolinha & Mastruz & & Fava \\
Pimentão & & & Girassol \\
Tomate & & & Palma Forrageira \\
\hline
\end{tabular}

\section{POLÊM!CA | Revista Eletronica da Uerj}

Rua São Francisco Xavier, 524, $2^{\circ}$ andar - BL D, sl 2025 - Maracanã 
Fonte: Os autores.

A expectativa do projeto é inserir a educação ambiental dentro do espaço escolar para despertar os alunos para as questões relacionadas ao meio ambiente. Desta forma busca-se promover um ensino contextualizado para a melhoria da qualidade de vida regional na qual estes estão inseridos.

A implantação da horta na escola é um momento que exige muita reflexão, estudos, dedicação e compromisso com as atividades que serão desenvolvidas, desde a limpeza da área até a manutenção dos canteiros e consequentemente a comercialização dos produtos, no caso as hortaliças.

Neste contexto os alunos tiveram a oportunidade de realizar, a partir de estudos em sala de aula, o planejamento, considerado etapa fundamental para desenvolver qualquer atividade. Durante esta etapa, foi reservado semanalmente um horário letivo de 45 minutos por semana, sendo na fase de implantação incrementado para dois horários letivos.

Percebe-se que com a implantação da horta na escola os alunos apresentaram um comportamento diferente, pois tiveram a oportunidade de realizar tarefas em grupo, pensando num todo, e desenvolveram um espírito cooperativo e participativo. Cabe ressaltar que os alunos despertaram o interesse pela pesquisa de temas importantes, como: os problemas ambientais, o uso dos recursos hídricos de forma correta, a importância da reciclagem e a importância das hortaliças para a alimentação humana, qualidade de vida, fatores que são fundamentais para promover o desenvolvimento sustentável.

Figura - 3: Confecção dos Canteiros do Projeto Horta na Escola Gurjão-PB

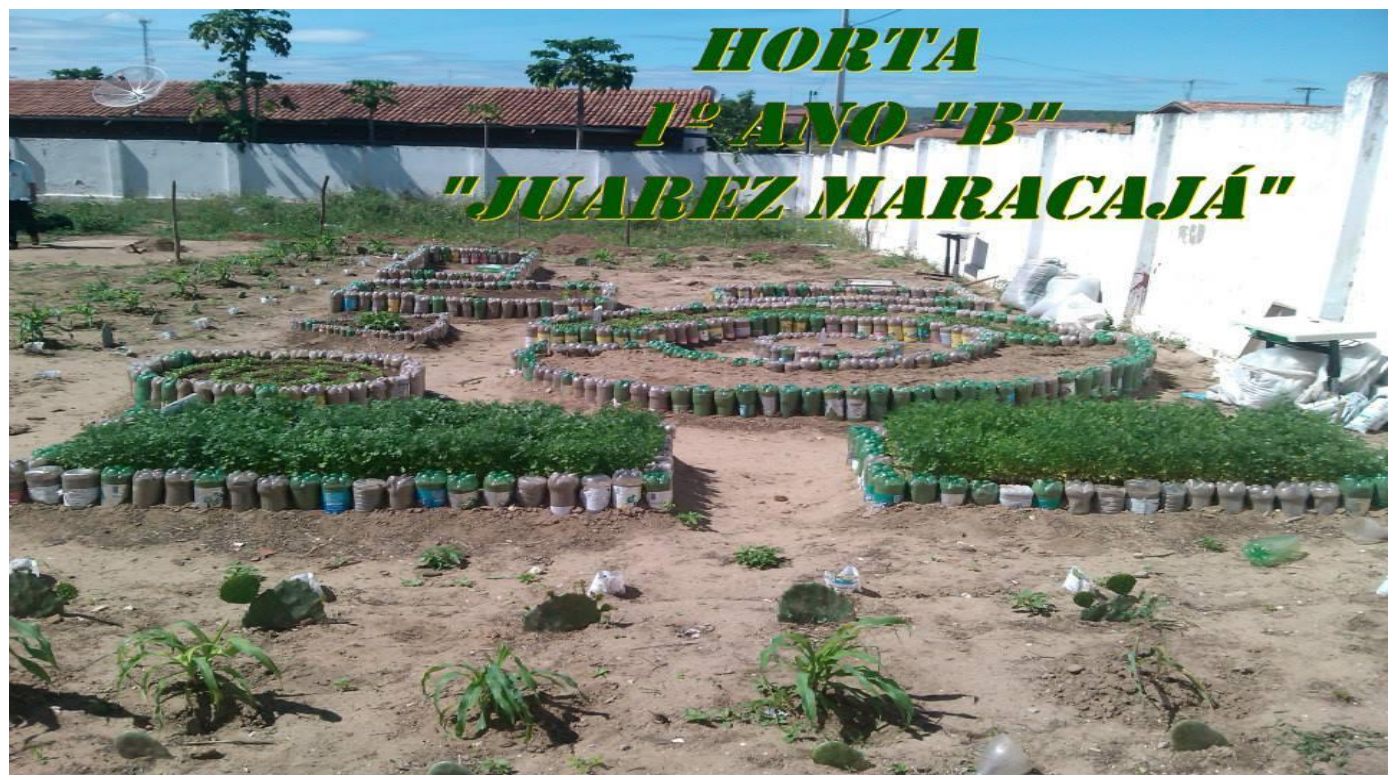

Fonte: Acervo Carlos Antônio G. da Costa (2013).

Entende-se que a escola é um espaço apropriado para melhorar o aprendizado nos campos teórico e prático desta temática e que os alunos, a partir das informações que lhes são passadas, poderão tornar-se agentes

\section{POLÊM!CA | Revista Eetrônica da veri}


de transformação de uma sociedade. O professor é fundamental na formação destes, pois permite que os alunos possam desenvolver todo seu potencial intelectual e artístico.

No tocante a necessidade de manejar ou gerenciar os recursos hídricos escassos na região fez-se necessário buscar alternativas que supram esta dificuldade. Para isso utilizou-se de uma tecnologia simples e de baixo custo colocando-se um saco plástico no interior dos canteiros para evitar a infiltração da água e mantê-los sempre úmidos, demonstrando que é possível conviver e produzir na região sem desperdício de água.

No primeiro ciclo de produção os alunos obtiveram 50 molhos de coentro; destes, parte foram doados para a escola utilizar na merenda e a outra parte foi comercializada pelos próprios alunos, onde a renda serviu para aquisição de sementes para o próximo ciclo de cultivo.

Nesta perspectiva, o projeto horta na escola visa promover um estudo interdisciplinar através da inserção da educação ambiental, contribuindo para uma melhoria no processo ensino-aprendizagem, no sentido de fortalecer a temática de desenvolvimento sustentável e fazer com que os alunos possam levar esta proposta para suas residências, havendo, com isso, a possibilidade de replicação do projeto e melhoria da qualidade de vida dos seus familiares.

\section{Conclusões}

A implementação no currículo escolar do macrocampo participação estudantil através da confecção da horta escolar possibilitou melhorias nas condições de aprendizado a partir de um projeto de aplicabilidade universal em um espaço favorável à interação do alunado.

Com a inserção da educação ambiental no currículo escolar, percebe-se nos alunos uma maior sensibilidade para com as questões ambientais e também de segurança alimentar, contribuindo, ainda, para a melhoria do trabalho coletivo e participativo entre os alunos, sendo a escola um ambiente privilegiado para se discutir e desenvolver atividades relacionadas à tais questões.

A presença de uma horta na escola amplia o espaço de aprendizado com um laboratório de campo que deve ser trabalhado de forma interdisciplinar, tornando-se fundamental para a formação de cidadãos conscientes e críticos com relação aos problemas ambientais, contribuindo também para melhorar e dinamizar o processo ensino-aprendizagem em um ambiente de reflexão e descontração.

Este tipo de atividade possui ampla capacidade de replicação tendo em vista, como apresentado, a necessidade de poucos recursos para estabelecê-la, gerando resultados positivos a favor do desenvolvimento sustentável.

\section{Referências}

ABÍLIO, F.J. P.; FLORENTINO, H. da S. Percepção e atividades integradoras de educação ambiental com educandos do ensino médio de Soledade-PB. João Pessoa: UFPB, 2008.

ABÍLIO, F.J. P.; GUERRA, R. A. T. (Org.). A questão ambiental no ensino de Ciências e a formação continuada de professores de ensino fundamental. João Pessoa: UFPB/FUNAPE, 2005.

CRIBB, S.L.de S.P. Contribuiç̃̃es da Educação Ambiental e Horta Escolar na promoção de melhorias ao ensino, à saúde e ao ambiente.REMPEC - Ensino, Saúde e Ambiente, v.3 n 1 p. 42-60 Abril 2010.

\section{POLÊM!CA | Revista Eletrônica da Uerj}

Rua São Francisco Xavier, 524, $2^{\circ}$ andar - BL D, sl 2025 - Maracanã 
CPRM - Serviço Geológico do Brasil, Projeto cadastro de fontes de abastecimento por água subterrânea. Diagnóstico do município de Gurjão, estado da Paraíba. Recife: CPRM/PRODEM, 2005. Disponível em: http://www.cprm.gov.br, Acesso em 21 de mai. 2015.

LOZANO, M.S.; MUCCI, J.L.N. A Educação Ambiental em uma escola da rede estadual de ensino no município de Santo André: análise situacional. Rev. Eletrônica Mestr. Educ. Ambient. Rio Grande, v. 14, p. 132-151, 2005.

MALVEZZI, R. Semiárido - uma visão holística. - Brasília: Confea, 2007.

NASCIMENTO, S.S.; ALVES, J.J.A. Ecoclimatologia do Cariri Paraibano. Rev. Geogr. Acadêmica. v.2 n.3. págs. 28-41, 2008.

MASSINE, M.C.L. Sustentabilidade e Educação Ambiental - Considerações acerca da política nacional de educação ambiental - A Conscientização ecológica em foco. Anais do XIX Encontro Nacional do CONPEDI, Fortaleza-CE, 2010.

MILARÉ, É. Direito do ambiente - a gestão ambiental em foco: doutrina, jurisprudência, glossário. 6. ed. rev., atual. e ampl. São Paulo: Revista dos Tribunais, 2009. p. 68-69.

MINISTÉRIO DA EDUCAÇÃO (MEC). Programa Ensino Médio Inovador: Documento Orientador. 2015.

SANTOS, A. S. R. dos. O direito ambiental e a participação da sociedade. In: BEJAMIN, Antônio Herman V.; MILARÉ, É. (Coord.). Revista de direito ambiental. São Paulo, n. 3, jul-set 1997, p. 219.

SILVA, P. K. O.; RAMOS, J. W. DE F.; ALVES, S. S.; ALBUQUERQUE, S. S. Atuação do macrocampo participação estudantil e sociologia no Severino Cabral. IV encontro de iniciação científica a docência da UFCG. Linguagens, Diversidade e Docência do PIBID - UFCG.

Recebido em: 09/06/2014.

Aceito em: 02/10/2015. 